\title{
Lactoferrin - A Novel Bone Growth Factor
}

\author{
Dorit Naot, PhD; Andrew Grey, MD; lan R Reid, MD and Jillian Cornish, PhD
}

\begin{abstract}
Lactoferrin is an iron-binding glycoprotein that belongs to the transferrin family. It is present in breast milk, in epithelial secretions, and in the secondary granules of neutrophils. In healthy subjects lactoferrin circulates at concentrations of $2-7 \times 10^{-6} \mathrm{~g} / \mathrm{ml}$. Lactoferrin is a pleiotropic factor with potent antimicrobial and immunomodulatory activities. Recently, we have shown that lactoferrin can also promote bone growth. At physiological concentrations, lactoferrin potently stimulates the proliferation and differentiation of primary osteoblasts and also acts as a survival factor inhibiting apoptosis induced by serum withdrawal. Lactoferrin also affects osteoclast formation and, in murine bone marrow culture, lactoferrin potently inhibits osteoclastogenesis. In vivo, local injection of lactoferrin above the hemicalvaria of adult mice results in substantial increases in the dynamic histomorphometric indices of bone formation and bone area.
\end{abstract}

The mitogenic effect of lactoferrin in osteoblast-like cells is mediated mainly through LRPI, a member of the family of low-density lipoprotein receptor-related proteins that are primarily known as endocytic receptors. Using confocal laser scanning microscopy, we demonstrated that fluorescently labeled lactoferrin is endocytosed and can be visualized in the cytoplasm of primary osteoblastic cells. Lactoferrin also induces activation of p42/44 MAPK signaling in primary osteoblasts, but the two pathways seem to operate independently as activation of MAPK signaling, but not endocytosis, is necessary for the mitogenic effect of lactoferrin. We conclude that lactoferrin may have a physiological role in bone growth and healing, and a potential therapeutic role as an anabolic factor in osteoporosis.

Keywords: Lactoferrin; Bone development; Bone remodeling; Bone regeneration; Anabolic agents; LDL-Receptor Related Protein I

steoporosis is defined as a reduction in bone mass and a change in microarchitecture, which increases the susceptibility to fracture. ${ }^{1}$ The bone loss results from imbalance between the activities of osteoclasts and osteoblasts that leads to uncoupling of bone resorption and bone formation. Osteoporosis is a major cause of morbidity and health expenditure in aging populations. ${ }^{2}$ Until recently, antiresorptive medications such as bisphosphonates and estrogens represented the main pharmacological treatment options for patients with osteoporosis. Despite their great therapeutic value, these agents are limited in their ability to restore bone mass, and reduce the incidence of osteoporotic fracture by $50 \%$ at best. ${ }^{3,4}$ Consequently, there is a great interest in the development of anabolic agents designed to increase bone mineral density by stimulating bone formation..$^{5}$ Currently, only

Reprint Requests: Dorit Naot, PhD, Department of Medicine, University of Auckland, Private Bag 92019, Auckland, New Zealand. Tel: 64-9-373-7599, ext 86258; Fax: 64-9-373-7677; Email: d.naot@auckland.ac.nz one anabolic agent, teriparatide, a recombinant formulation of a fragment of parathyroid hormone (PTH), has been approved for the treatment of osteoporosis, ${ }^{6}$ and there is an intensive search for other potential therapeutic compounds with anabolic effects in bone.

Milk is a rich biological fluid that contains many growth factors, and provides nutrition at a time of very rapid skeletal growth and development in the neonate. Therefore, it was considered as a possible source of factors with anabolic effects on bone. We found that a number of fractions of whey protein extracted from milk have growth stimulatory effects in primary cultures of osteoblasts. High performance liquid chromatography analysis of the major proteins in the active fractions identified the presence of the glycoprotein lactoferrin in most of these fractions.

Received: February $21,2005 \quad$ Revised:April 5, 2005

Accepted:April 5, 2005

Research Support: Health Research Council of New Zealand and LactoPharma Consortium 
Lactoferrin is an $80 \mathrm{kDa}$ iron-binding glycoprotein produced by many exocrine glands and is also a major constituent of the secondary granules of neutrophilic leukocytes. ${ }^{7-9}$ Serum levels of lactoferrin are predominantly neutrophil-derived and in healthy subjects range from $2 \mu \mathrm{g} / \mathrm{ml}$ to $7 \mu \mathrm{g} / \mathrm{ml}$, but during inflammation its local concentrations are much higher. ${ }^{10}$ Lactoferrin acts as an iron-chelator, which may contribute to its antimicrobial activity, ${ }^{11}$ but it also has effects on cell growth and differentiation, ${ }^{12}$ embryonic development, ${ }^{13}$ myelopoiesis, ${ }^{14}$ endothelial cell adhesion, ${ }^{15}$ cytokine $^{16,17}$ and chemokine ${ }^{18}$ production, regulation of the immune system, ${ }^{19}$ and modulation of the inflammatory response. ${ }^{20}$

We investigated the effects and mechanism of action of lactoferrin in bone cells in vitro and in a local injection model in vivo. ${ }^{21,22}$ These studies established lactoferrin as a novel anabolic factor in osteoblasts, which also reduces osteoclast differentiation, causing an overall effect of increase in bone mass through the promotion of bone formation and the inhibition of bone resorption.

\section{Lactoferrin Stimulates Proliferation and Differentiation of Osteoblast-Like Cells}

The effect of lactoferrin on osteoblast-like cell proliferation was measured using a thymidine incorporation assay. ${ }^{21}$ Lactoferrin purified from bovine milk produced a dose-related increase in thymidine incorporation in primary rat osteoblasts (figure 1A). Similar proliferative effects were observed in primary human osteoblasts and in the two cell lines: human osteoblast-like cell line, SaOS-2, and stromal cell line, ST2.21 The concentrations of lactoferrin that stimulated cell proliferation were within the physiological range. Recombinant human lactoferrin that was produced in mammalian cells also potently stimulated the proliferation of rat primary osteoblasts (figure 1B) excluding the possibility that the proliferative effect seen with the bovine lactoferrin was due to minute quantities of other growth factors co-purifying with lactoferrin or residual lipopolysaccharide (LPS) in the bovine lactoferrin preparation.

The effect lactoferrin has on osteoblast differentiation was investigated using a bone nodule formation assay. Confluent cultures of primary rat osteoblasts were treated with lactoferrin for 17 to 18 days in media supplemented with L-ascorbic acid-2-phosphate and $\beta$-glycerophosphate that induce osteoblast differentiation. They were then fixed and stained by Von Kossa stain. The process of bone nodule formation involves the two bone-forming activities of the differentiated osteoblasts: bone matrix deposition and mineralization. Lactoferrin, at concentrations of $100 \mu \mathrm{g}$ and above, significantly stimulated the number of nodules and increased the mineralized area (figure 1C).

The effect of lactoferrin on apoptosis of osteoblasts was also studied, as the inhibition of cell death is an additional way to expand the population of osteoblasts. Apoptosis, induced in primary rat osteoblasts by a 24-hour period of serum deprivation, was inhibited $50 \%$ to $70 \%$ by lactoferrin as judged by the number of cells stained with deoxynucleotidyl transferase-mediated deoxyuridine triphosphate nick-end labeling (TUNEL) (figure 1D).

Thus, lactoferrin increases the number of osteoblasts capable of synthesizing new bone both through stimulation of proliferation and inhibition of cell death. It also enhances the ability of the osteoblasts to synthesize and mineralize bone matrix.

\section{Lactoferrin Inhibits Osteoclastogenesis}

Factors that stimulate osteoblast proliferation and differentiation can affect osteoclasts in different ways. Some coupling factors, such as PTH, accelerate bone turnover by inducing the activities of both osteoclasts and osteoblasts while other factors, such as amylin ${ }^{23,24}$ and interleukin (IL)-18, ${ }^{25}$ induce the bone forming activity of osteoblasts and inhibit bone resorption by osteoclasts thus promoting bone accrual. Several in vitro assays were used to investigate the effect of lactoferrin on osteoclast differentiation and activity. In a mouse bone marrow culture, the number of multinucleated cells staining positively for tartrate-resistant acid phosphatase (TRAP) after 8 days in culture is a measure of osteoclastogenesis. In these cultures, lactoferrin (added on day 2 and day 4) potently inhibited osteoclast formation in a dose dependent manner showing complete arrest of osteoclastogenesis at a lactoferrin concentration of $100 \mu \mathrm{g} / \mathrm{ml}$ (figure 2A). In another study of the effects of lactoferrin on bone resorption, Lorget et al. ${ }^{26}$ demonstrated that bovine lactoferrin reduces bone-resorbing activity in a rabbit mixed-bone cell culture. This effect appeared to be mediated by an inhibition of the development of mature osteoclasts.

The effect of lactoferrin on the activity of mature osteoclasts was measured in an isolated osteoclast culture. ${ }^{21}$ In this assay, an osteoclast-rich suspension from rat long bones is cultured for 20 hours on bone slices. After counting the TRAP-positive multinucleated cells per slice, the number of pits excavated by these osteoclasts is determined. The number of pits per osteoclast is a measure of the mature osteoclast activity. Lactoferrin had no effect in these cultures at concentrations of up to $100 \mu \mathrm{g} / \mathrm{ml}$ (figure $2 \mathrm{~B}$ ). In a neonatal mouse calvarial organ culture prepared from mice that had been previously injected with ${ }^{45} \mathrm{Ca}$, the release of ${ }^{45} \mathrm{Ca}$ into the media is a measure of mature osteoclast activity. The results from this experimental system were consistent with the isolated osteoclast assay, confirming that lactoferrin does not affect mature osteoclast activity. Taken together, these results indicate that although lactoferrin does not affect the activity of fully differentiated osteoclasts to resorb bone, it inhibits bone resorption by reducing the number of osteoclasts formed from precursor cells.

\section{Lactoferrin Increases Bone Growth In Vivo}

A local injection model was used to study the effect of lactoferrin on bone in vivo. ${ }^{21}$ Lactoferrin was administered over the right hemicalvarium of adult male mice for 5 
A

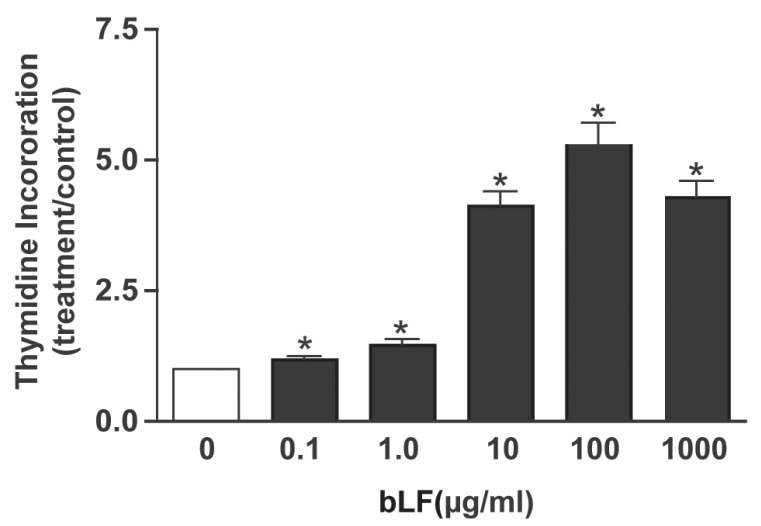

B

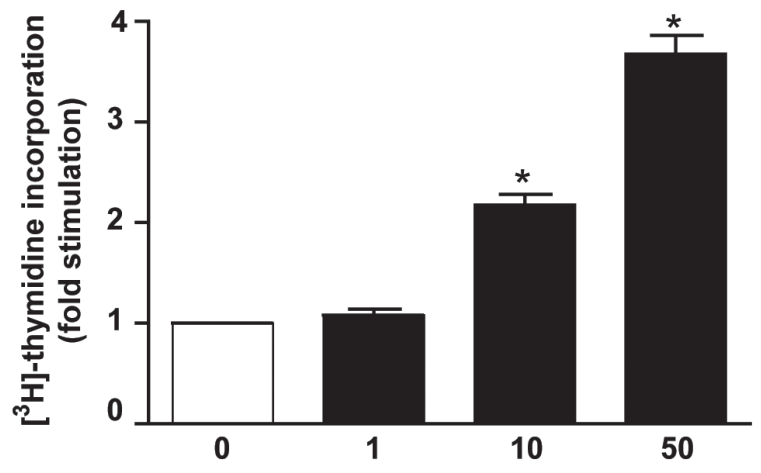

C
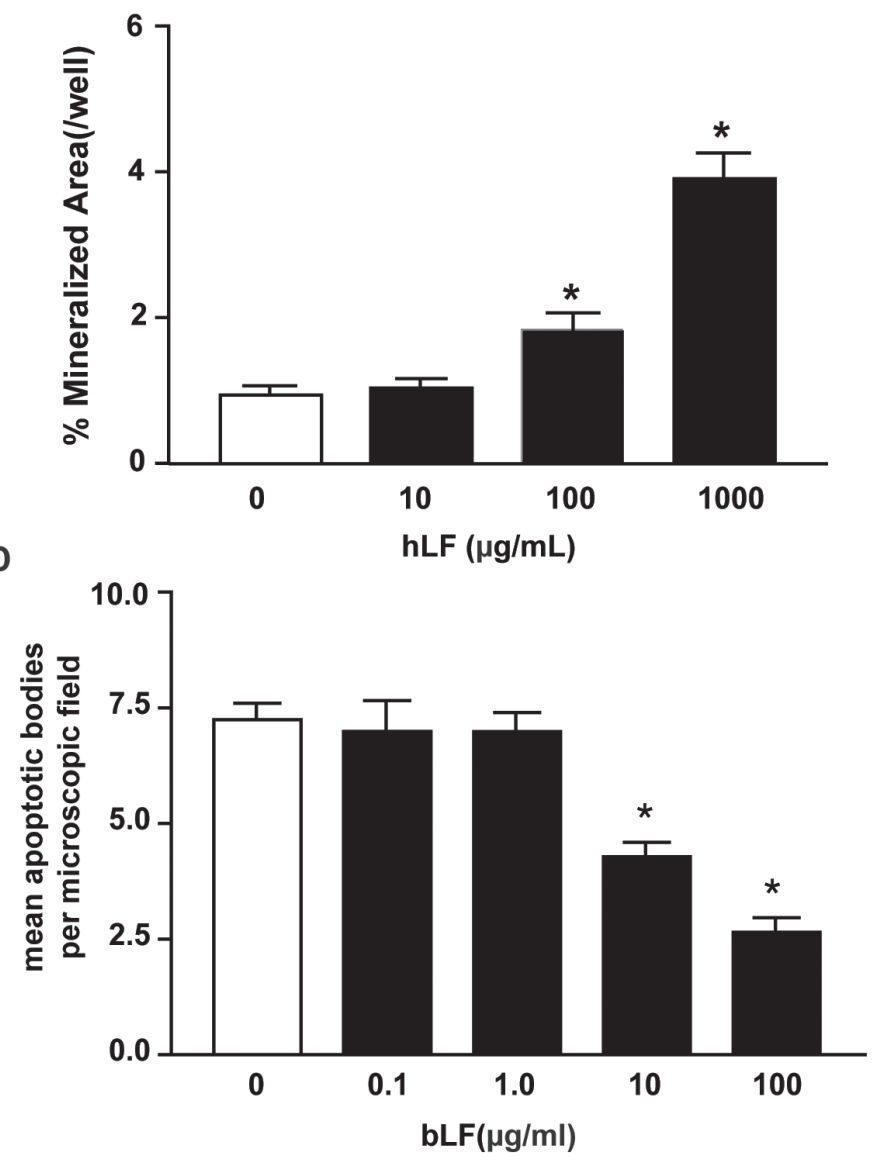

consecutive days while the fluorochrome labels, calcein and alizarin red, were injected subcutaneously on days 1,5 , and 14. These fluorochromes incorporate specifically into ossifying bone, and their sequential addition is used to mark the timing and location of osteoid deposition and mineralization in vivo. The animals were sacrificed 24 hours after the last fluorochrome administration. Sections from the calvaria of the lactoferrin treated mice were compared to calvaria from mice injected with albumin or with vehicle only. No changes were observed between the albumin and the vehicle-only groups, indicating that there was no nonspecific effect of protein injection. As shown in figure 3, the distance between the first fluorochrome label and the bone surface (i.e., the measure of new bone formation) was greatly increased by lactoferrin. Assessment of dynamic histomorphometric indices indicated significant increases in mineral apposition rate and bone formation rate induced by lactoferrin. The potent effect of lactoferrin on bone area in vivo, as demonstrated in figure 3 , is most likely the result of the combined anabolic effects of lactoferrin on osteoblasts and the inhibitory effect on osteoclastogenesis that were seen in vitro.

\section{Mechanisms of Action in Osteoblasts}

The molecular mechanisms by which lactoferrin acts at the cellular level are largely unknown. Specific lactoferrin receptors have been described in mammalian cell types and tissues including monocytes, lymphocytes, platelets, liver, mammary epithelial cells, and intestine. ${ }^{27}$ Many of these receptors have not yet been fully characterized or cloned, but lactoferrin was able to bind in a reversible, saturable, and specific manner to all these cell types and tissues. Among the putative lactoferrin receptors are the low-density lipoprotein receptor-related proteins-1 and -2 (LRP1 and LRP2) ${ }^{28-31}$ which are multi-ligand members of the LRP family of endocytic receptors. ${ }^{32}$ Binding of lactoferrin to LRP1 and LRP2 was initially demonstrated during investigation of the

Figure 1. Effects of lactoferrin on osteoblast proliferation, differentiation and survival. Thymidine incorporation in primary cultures of rat osteoblast-like cells treated for 24 hours with increasing concentrations of (A) bovine lactoferrin (bLF) or (B) recombinant human lactoferrin (hLF). (C) The effect of lactoferrin on areas of mineralized bone nodules as determined in primary cultures of rat osteoblast-like cells cultured over a period of 3 weeks. Cells were stained for mineral using Von Kossa stain. (D) Effect of bovine lactoferrin on apoptosis observed in response to a 24-hour period of serum deprivation in cultures of primary rat osteoblast-like cells, as judged by the number of TUNEL-positive cells. Data are mean \pm SEM. * , significantly different from control $(P<0.05)$. (Adapted and reproduced with permission. Panel A, C, D: Cornish et al. Lactoferrin is a potent regulator of bone cell activity and increases bone formation in vivo. Endocrinology 2004;145:4366-4374. Epub May 27, 2004. Panel B: Grey et al. The low-density lipoprotein receptor-related protein 1 is a mitogenic receptor for lactoferrin in osteoblastic cells. Mol Endocrinol 2004;18:2268-2278. Epub June 3, 2004. Copyright 2004 The Endocrine Society) 


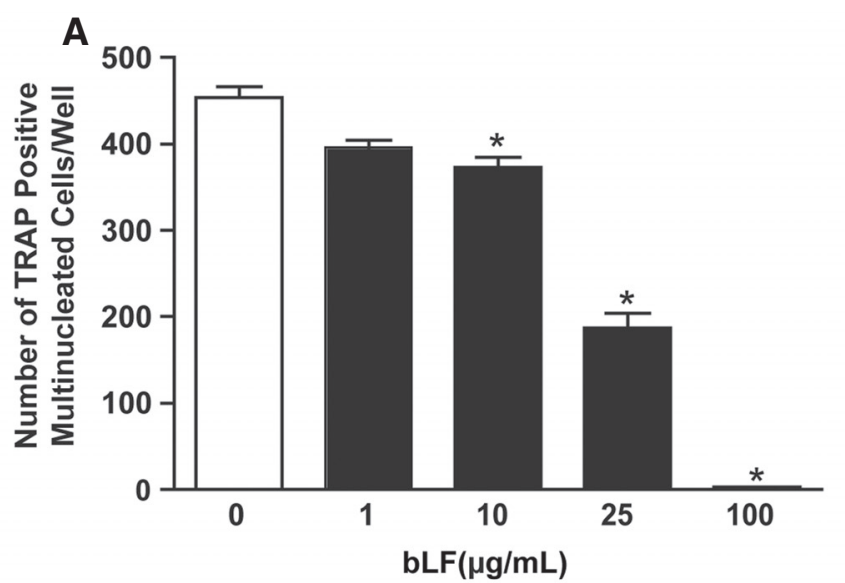

B

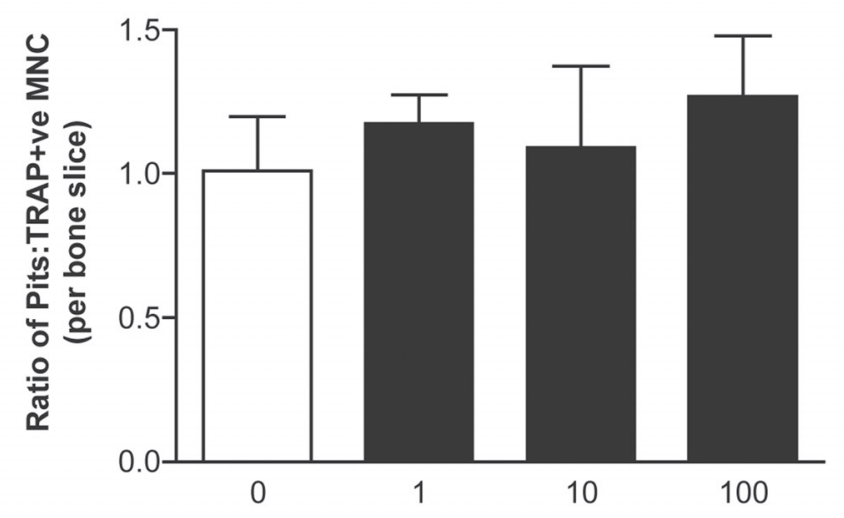

Figure 2. (A) Effects of bovine lactoferrin on osteoclast development in mouse bone-marrow cultures. The number of newly developed osteoclasts, assessed as multinucleated cells (MNC) staining positively for TRAP, was significantly decreased by lactoferrin in concentrations of $10 \mu \mathrm{g} / \mathrm{ml}$ and greater. (B) Effect of bovine lactoferrin on bone resorption by isolated mature osteoclasts (assessed as resorption pits per osteoclast). There were no statistically significant effects. Data are mean \pm SEM. * significantly different from control $(P<0.05)$. (Reproduced with permission. Cornish et al. Lactoferrin is a potent regulator of bone cell activity and increases bone formation in vivo. Endocrinology 2004;145:4366-4374. Epub May 27, 2004. Copyright 2004 The Endocrine Society)

inhibitory effect of lactoferrin on the hepatic clearance of chylomicron remnants. ${ }^{28,33}$ Later, lactoferrin was shown to stimulate a G-protein-dependent signaling pathway which regulated receptor mediated endocytosis via LRP. ${ }^{34}$ Recent evidence suggests that LRP1 functions both as an endocytic receptor and a signaling receptor. $32,35,36$

The $39 \mathrm{kDa}$ receptor-associated protein (RAP) has been shown to co-purify and bind in vitro with high affinity to both LRP1 and LRP2. Although early studies localized RAP to the cell surface, Willnow et al. ${ }^{37,38}$ showed that RAP is predominantly localized in the endoplasmic reticulum and suggested that it acts as a chaperone in the biosynthesis of LRP1 and LRP2, preventing premature ligand binding during receptor trafficking. RAP was a useful tool in the study that aimed to establish the role of LRP1 and LRP2 in lactoferrin signaling in
A

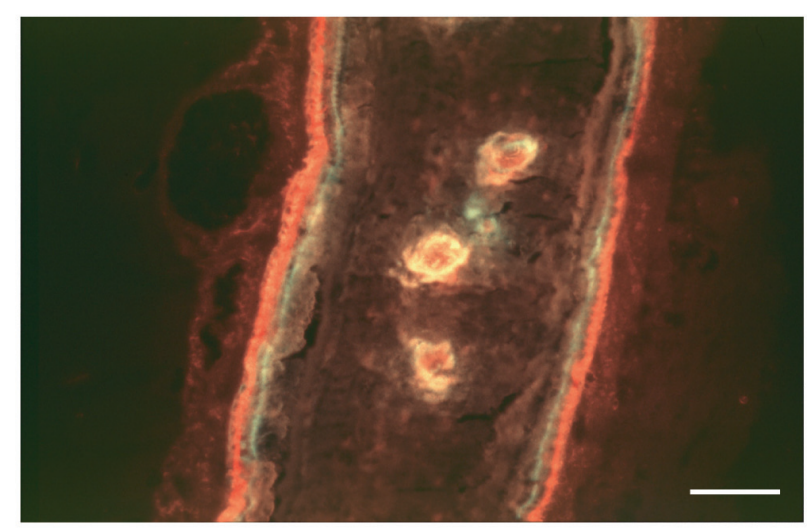

B

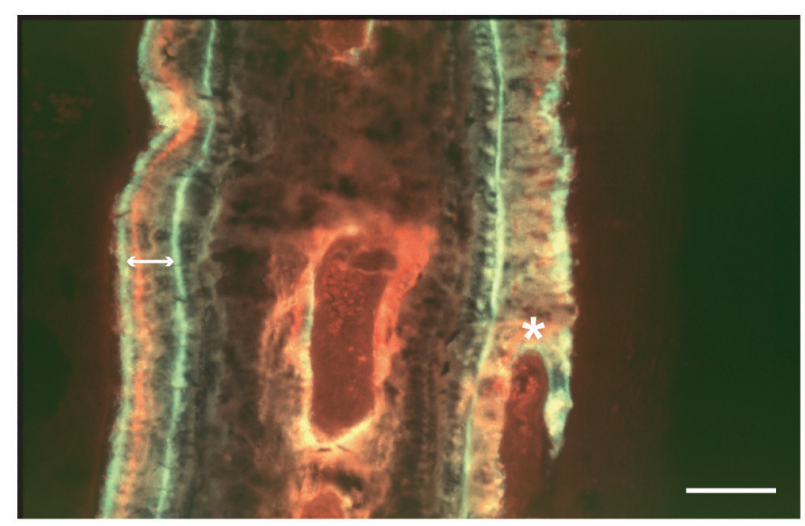

Figure 3. Photomicrographs of calvariae from animals treated with (A) vehicle and (B) lactoferrin (4 mg) for 5 days. Fluorochrome labels used: green=calcein, red=alizarin. Two calcein labels were given 13 days apart. The increased new bone growth in the 13-day period (i.e., distance between the 2 green calcein labels, arrowed) can be appreciated in the calvaria from the lactoferrin-treated animal. It can also be noted that there is new bone marrow formation occurring within the recently formed bone in the lactoferrin-treated calvaria. New bone formed on the injected side of the lactoferrin calvaria is partially woven (asterisk). This was only seen in the animals treated with the highest dose of lactoferrin, and probably reflects the very high rate of matrix deposition. The horizontal bar represents $50 \mu \mathrm{m}$. (Reproduced with permission. Cornish et al. Lactoferrin is a potent regulator of bone cell activity and increases bone formation in vivo. Endocrinology 2004;145:4366-4374. Epub May 27, 2004. Copyright 2004 The Endocrine Society)

osteoblasts, as it can be added externally to the cells and specifically inhibits ligand binding to both receptors.

\section{Lactoferrin is Endocytosed by Osteoblastic Cells}

The expression of LRP1 and LRP2 in primary osteoblasts and in several osteoblastic cell lines was investigated by reverse transcription-polymerase chain reaction (RT-PCR). LRP1 and LRP2 mRNAs were present in primary neonatal rat calvarial osteoblasts, the osteoblastic cell lines UMR-106 and MC3T3E1, and the ST2 stromal cell line. The osteoblastic SaOS-2 cell line expressed LRP1 but not LRP2.22 
LRP1 and LRP2 have primarily been studied as endocytic receptors while lactoferrin was shown to be endocytosed by several different cell types. Therefore, the possibility that lactoferrin acts on osteoblasts through binding to LRP and entering the cell itself was investigated. Confocal microscopic analysis showed that Oregon-Green labeled lactoferrin could be visualized inside the cells 30 minutes after addition to cultures of primary rat osteoblasts (figure 4A). Co-staining with the membrane label DiI (1,1'-dioctadecyl-3,3,3',3'tetramethylindocarbocyanine perchlorate) demonstrated co-localization of the cytoplasmic lactoferrin with intracellular vesicles (figure 4B-D). The appearance of labeled lactoferrin inside the cells (figure 4E) was the result of a physiological process of endocytosis since under conditions that are known to inhibit endocytosis, including the use of hypertonic medium or placing the cultures at $4{ }^{\circ} \mathrm{C}$, no lactoferrin could be detected in the cytoplasm (figure $4 \mathrm{~F}-\mathrm{G}$ ). Pre-treatment of the cells with RAP also abolished the endocytosis of lactoferrin by primary osteoblasts (figure $4 \mathrm{H}$ ) demonstrating that lactoferrin is endocytosed by osteoblastic cells via a mechanism that involves functional LRP1 or LRP2.

\section{Mitogenic Actions in Osteoblasts Involve Activation of p42/44 MAP Kinases}

Although members of the LRP family were mainly described as endocytic receptors, recent evidence suggests that they also act as signaling receptors. The study of possible signal transduction pathways involved in the mitogenic activity of lactoferrin in primary osteoblasts showed that lactoferrin induced the phosphorylation of p42/44 MAP kinases. ${ }^{22}$ This phosphorylation could be inhibited by the addition of RAP to the cell cultures indicating that the mitogenic signal is mediated via LRP1 or LRP2. The significance of p42/44 MAP kinase phosphorylation to the transduction of the mitogenic signal was established by the use of two specific inhibitors of MAP kinase kinase: PD-98059 and U-0126. Treatment of primary osteoblast cultures with either of these agents inhibited the mitogenic effect of lactoferrin in a dose-dependent manner implying that lactoferrin-induced osteoblast mitogenesis involves RAP-sensitive phosphorylation of p42/44 MAP kinases.

It is therefore apparent that two pathways are activated as a consequence of the interaction of lactoferrin with LRP1 or LRP2 on osteoblasts, endocytosis of lactoferrin, and activation of p42/44 MAP kinases. To investigate whether these pathways operate independently or downstream of one another, we studied the phosphorylation state of p42/44 MAP kinases when cells were treated with lactoferrin under three different conditions where endocytosis is inhibited: placing the cells at $4^{\circ} \mathrm{C}$ (figure 5), using hypertonic medium, or using phenylarsine oxide, a pharmacological inhibitor of endocytosis. Each of these treatments inhibited endocytosis of lactoferrin but had no effect on MAP kinases activation. Therefore, we conclude that, in this biological system, endocytosis and phosphorylation of p42/44 MAP kinases are independent of each other and that endocytosis is not required for the transduction of the mitogenic signal.
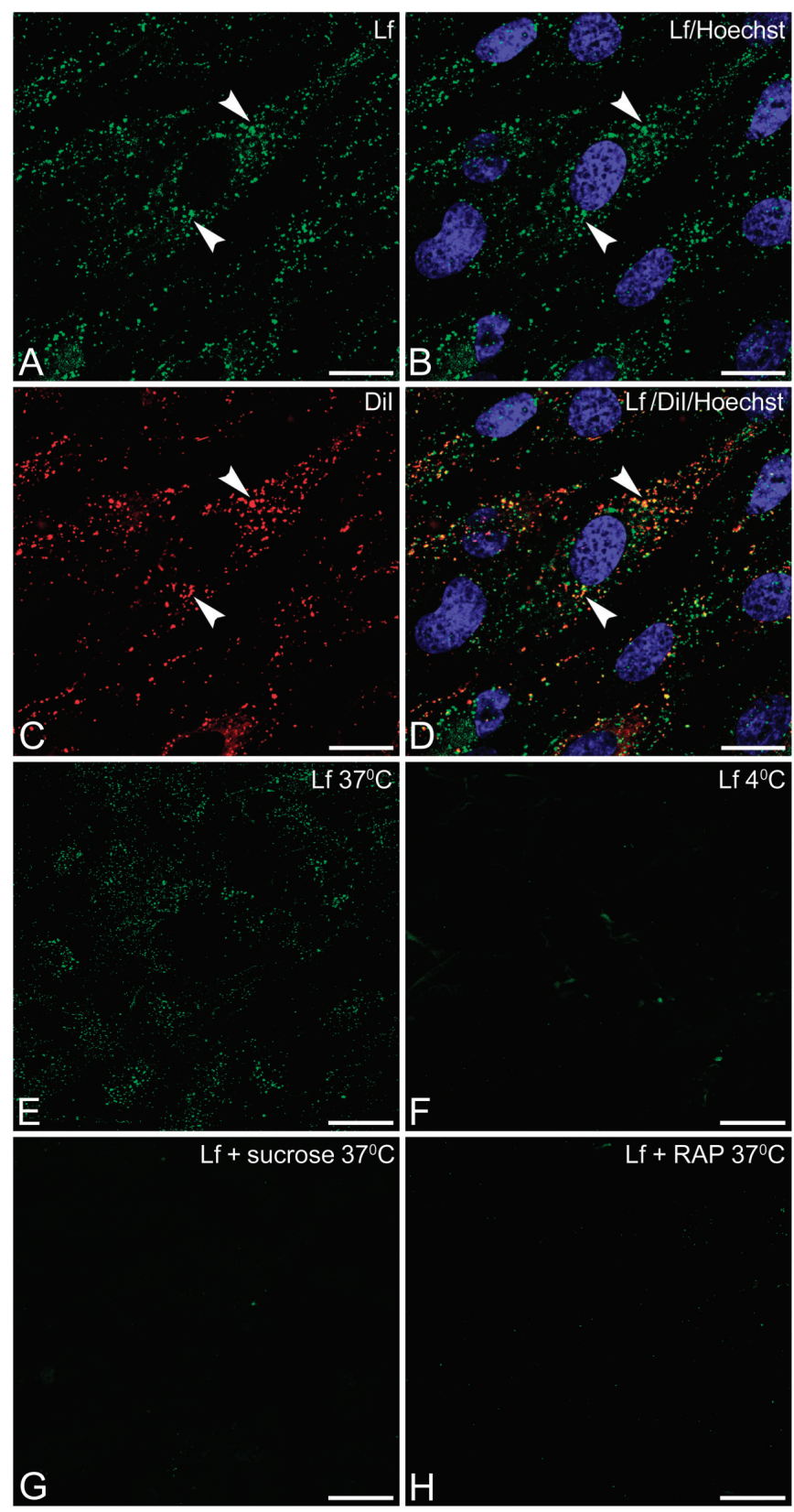

Figure 4. Osteoblastic cells endocytose lactoferrin in a RAP-sensitive fashion. Upper panel: Confocal micrographs showing single optical sections of primary rat osteoblastic cells labeled with (A) Oregon Green-conjugated lactoferrin for 30 minutes at $37^{\circ} \mathrm{C},(B)$ the nuclear stain Hoechst 33258, (C) the membrane stain Dil, (D) overlay of images A-C demonstrating co-localization of lactoferrin with intracellular, cytoplasmic vesicles (arrowheads). Lower panel: Confocal micrographs showing single optical sections of primary rat osteoblastic cells labeled with $(E)$ Oregon Green-conjugated lactoferrin for 30 minutes at $37^{\circ} \mathrm{C}$, (F) Oregon Green-conjugated lactoferrin for 60 minutes at $4^{\circ} \mathrm{C},(\mathrm{G})$ Oregon Green-conjugated lactoferrin for 30 minutes at $37^{\circ} \mathrm{C}$ in the presence of $400 \mathrm{nM}$ sucrose, $(\mathrm{H})$ Oregon Green-conjugated lactoferrin for 30 minutes at $37^{\circ} \mathrm{C}$ in the presence of $50 \mathrm{nM}$ RAP. Scale bars, $20 \mu \mathrm{m}$ (A-D); $40 \mu \mathrm{m}$ (E-H). (Reproduced with permission from Grey et al. The low-density lipoprotein receptor-related protein 1 is a mitogenic receptor for lactoferrin in osteoblastic cells. Mol Endocrinol 2004;18:2268-2278. Epub June 3, 2004. Copyright 2004 The Endocrine Society) 


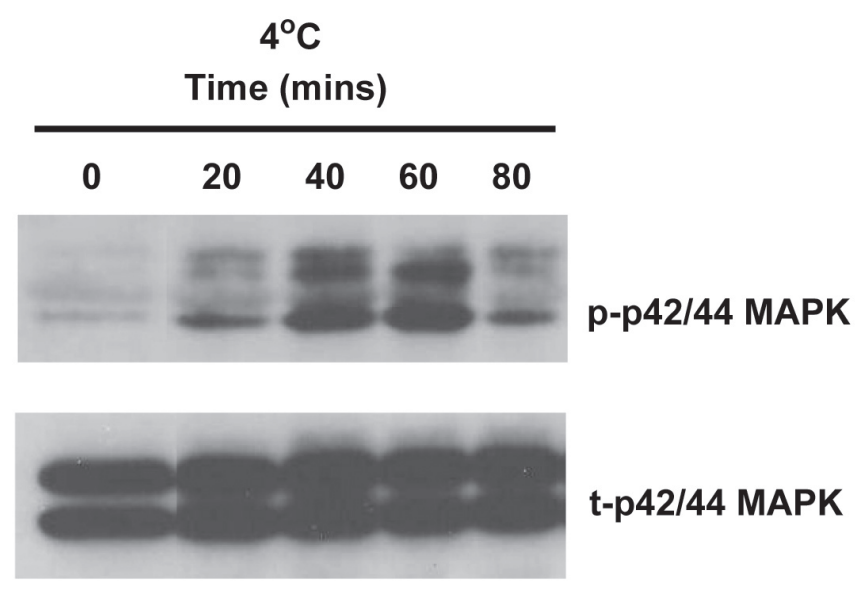

Figure 5. Endocytosis of lactoferrin is not required for activation of mitogenic signaling. Primary rat osteoblastic cells were placed at $4^{\circ} \mathrm{C}$ for 15 minutes and then treated with lactoferrin $(100 \mu \mathrm{g} / \mathrm{ml})$ for the indicated times. Whole cell lysates were sequentially immunoblotted with an antibody to phosphorylated p42/44 MAP kinases (top) and an antibody to total p42/44 MAP kinases (bottom). (Reproduced with permission from Grey et al. The low-density lipoprotein receptor-related protein 1 is a mitogenic receptor for lactoferrin in osteoblastic cells. Mol Endocrinol 2004;18:2268-2278. Epub June 3, 2004. Copyright 2004 The Endocrine Society)

\section{Mitogenic Actions in Osteoblasts are Mediated by LRP I} The ability of RAP to inhibit lactoferrin-induced osteoblast proliferation indicates a role for LRP1/LRP2. RAP inhibition of cell proliferation is not attributable to cell toxicity, since addition of RAP alone to the cell cultures had no effect on thymidine incorporation. RAP inhibition also is not nonspecific since RAP did not inhibit the mitogenic actions of the phospholipid growth factor lysophosphatidic acid (LPA) that signals through a $\mathrm{G}$ protein-coupled receptor (figure 6A). The use of RAP does not allow discrimination between the individual contributions of LRP1 and LRP2 because both receptors are expressed in primary rat osteoblasts and RAP inhibits binding of ligands to both receptors. 39

Several experimental systems were used to differentiate between the contributions of LRP1 and LRP2 to the transduction of the mitogenic signal of lactoferrin. Pre-treatment of primary rat osteoblastic cells with an LRP1 antibody that inhibits ligand binding ${ }^{40}$ blocks the proliferative response to lactoferrin (figure 6A). In addition, lactoferrin promotes mitogenesis in a dose-dependent manner in SaOS-2 cells, which express LRP1 but not LRP2. Lactoferrin-induced proliferation of SaOS-2 cells is also blocked by co-treatment with RAP. Taken together, these data strongly suggest that LRP1 functions as a mitogenic receptor for lactoferrin in osteoblastic cells.

The availability of a fibroblastic cell line established from LRP1-deficient mice (PEA13, LRP1-null) enabled a direct comparison of the mitogenic effects of lactoferrin in these cells to the effects in a fibroblastic cell line that expresses wild-type LRP1 (MEF-1, LRP1-wt). As shown in figure 6B, LRP1-wt cells proliferate in response to lactoferrin, while the proliferation of the LRP1-null cells was significantly abrogated. Further, addition of RAP to cultures of LRP1-wt cells reduced the proliferative response to a level equivalent to that observed in the LRP1-null cells. These data provide direct evidence that LRP1 functions as a mitogenic receptor for lactoferrin.

\section{Discussion}

The studies reviewed here provide the first evidence that lactoferrin is a promoter of osteoblast growth that also acts as an inhibitor of osteoclastogenesis in vitro, and increases local bone formation in vivo. ${ }^{21,22,41}$ The effects of lactoferrin on proliferation and survival of osteoblasts exceed those of other established anabolic factors that were tested in the same in vitro assays including transforming growth factor- $\beta$, PTH, amylin, and insulin. ${ }^{42}$ The combination of increased osteoblast proliferation, survival, and differentiation together with inhibition of osteoclast formation are likely to contribute to the potent stimulation of bone formation seen in the in vivo model following the administration of lactoferrin. The bone growth resulting from local lactoferrin injection is considerably greater than what we have found previously in response to factors such as insulin, amylin, adrenomedullin, C-terminal PTH-related peptide, calcitonin, or calcitonin gene-related peptide in the same model.24,43-45 Further examination of the animals that were locally injected with lactoferrin showed increases in new bone formation on the intracranial aspect of the calvariae and on the contralateral, uninjected hemicalvariae. This observation provides further evidence that lactoferrin is a very potent bone growth factor. However, its effect on bone formation in a long-term, systemic model remains to be established.

It is possible that lactoferrin has a physiological role in skeletal development or homeostasis. Lactoferrin is expressed in the embryo ${ }^{13}$ and could play a role in the development and function of chondrocytes and osteoblasts in the fetal skeleton. Lactoferrin is present in very high concentrations in colostrum as well as in milk. There is some evidence that large proteins, such as lactoferrin, can cross the neonatal gut and enter the systemic circulation. ${ }^{46}$ Thus, it is possible that the anabolic actions of lactoferrin might continue into the neonatal period. In adult animals, although some groups studied the biological effects of orally administered lactoferrin, ${ }^{47-49}$ the effect on bone formation has not been determined. The main source of lactoferrin in the circulation of the adult is the secondary granules of neutrophils. A recent study suggests that mice have a large reservoir of functionally competent neutrophils in their bone marrow ${ }^{50}$ which implies that under certain physiological conditions bone cells could be exposed to a high local concentration of lactoferrin. Systemic levels of lactoferrin can reach concentrations as high as $200 \mu \mathrm{g} / \mathrm{ml}$ during inflammation..$^{51}$ Therefore, in these inflammatory states, lactoferrin may play a role in counter-balancing the catabolic effects on the skeleton from some of the mediators of the inflammatory response. Lactoferrin plays an important immunomodulatory 
A

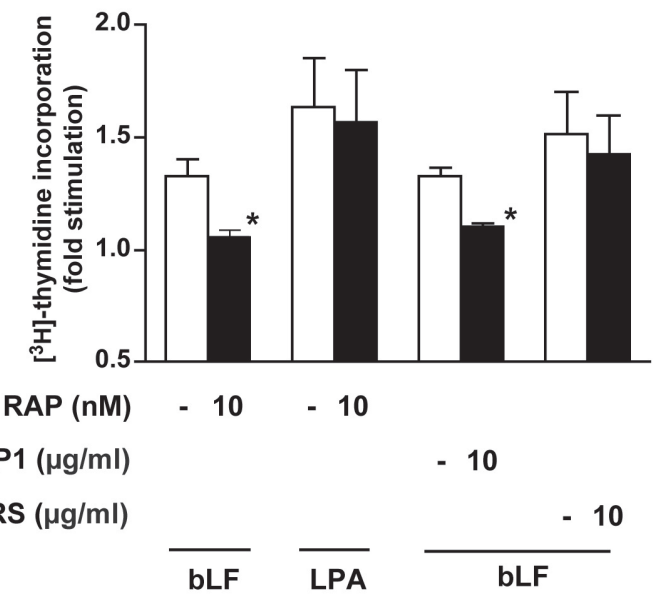

B

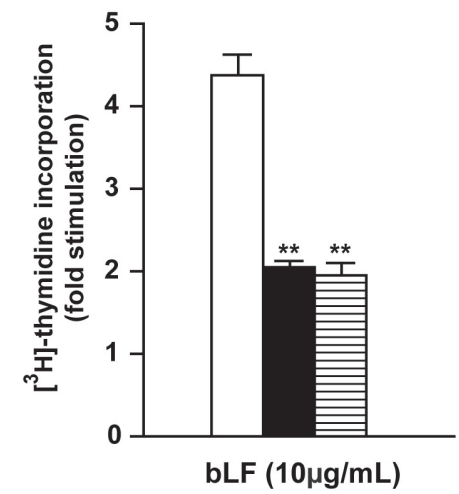

Figure 6. Lactoferrin-induced osteoblast mitogenesis is LRP1-dependent. (A) Growth-arrested primary rat osteoblastic cells were treated for 24 hours with either $10 \mu \mathrm{g} / \mathrm{ml}$ lactoferrin or $10 \mu \mathrm{M}$ lysophosphatidic acid (LPA) in the absence (open bars) or presence (shaded bars) of $10 \mathrm{nM}$ RAP, an antibody to LRP1 $(\alpha-$ LRP 1 ) or non-immune rabbit serum (NRS). Data are presented as the fold stimulation of $\left[{ }^{3} \mathrm{H}\right]$-thymidine incorporation induced by lactoferrin treatment over vehicle treatment (open bars), or that induced by treatment with lactoferrin + inhibitor over inhibitor treatment (shaded bars). ${ }^{*}, P<0.05$ versus lactoferrin. (B) Lactoferrin-induced mitogenesis is abrogated in LRP1-deficient fibroblasts. Growth-arrested fibroblastic cells expressing wild-type LRP1 (LRP1-wt, open bars) or inactivated LRP1 (LRP1-null, dark bars) were treated with lactoferrin (LF) for 24 hours. The hatched bar represents treatment with $10 \mu \mathrm{g} / \mathrm{ml}$ lactoferrin of LRP1-wt cells in the presence of 25 nM RAP. Data are presented as the fold stimulation of $\left[{ }^{3} \mathrm{H}\right]$-thymidine incorporation. ${ }^{* *}, P<0.01$ versus LRP-wt cells. (Reproduced with permission from Grey et al. The low-density lipoprotein receptor-related protein 1 is a mitogenic receptor for lactoferrin in osteoblastic cells. Mol Endocrinol 2004;18:2268-2278. Epub June 3, 2004. Copyright 2004, The Endocrine Society)

function ${ }^{20}$ decreasing the secretion of a number of osteolytic cytokines. Therefore, its direct effects on the activity and development of bone cells appear to be complemented by these cytokine-mediated effects.

The physiological role of lactoferrin has recently been studied in lactoferrin-deficient mice produced by homologous gene targeting. ${ }^{52}$ The mice were viable and fertile, developed normally, and displayed no overt abnormalities, although their skeletal phenotype has not been determined in detail. It is possible that in the absence of lactoferrin, as is sometimes seen in deficient mice models, other similar proteins can substitute and provide the missing functions.

The identification of LRP1 as a functional lactoferrin receptor in osteoblasts $^{22}$ provides a mechanistic explanation for the anabolic skeletal actions of lactoferrin and suggests a novel pathway through which bone anabolism might be regulated physiologically and/or pharmacologically. A recently published report also demonstrated the expression of LRP1 in osteoblastic cell lines and suggested a role for LRP1 in delivery of lipoproteins and vitamin $\mathrm{K} 1$ to bone. ${ }^{53}$ It is noteworthy, in this regard, that LRP5 and LRP6 (non-endocytic members of the LRP receptor family that are structurally related to LRP1) have been recently identified as critical regulators of osteoblast function and skeletal mass. $.54,55$ Whether there is overlap between the skeletal functions of these two receptors and that of LRP1 is currently unclear.

The development of lactoferrin as a pharmaceutical or "nutriceutical" agent is still in the early stages. Different formulations of lactoferrin are being designed and tested to optimize its bioavailability. The animal studies need to be extended to include a systemic administration model, as well as models of increased bone resorption, such as ovariectomy. The mechanisms of action of lactoferrin on bone cells also require further investigation as the pathways through which lactoferrin acts to inhibit osteoclastogenesis are largely unknown. It would be interesting to determine changes in gene expression levels induced by lactoferrin in bone cells and to study the interactions of lactoferrin signaling with other pathways that are known to play a major role in bone physiology.

In summary, the naturally occurring glycoprotein, lactoferrin, is anabolic to bone in vivo, an effect that is consequent upon its potent proliferative, differentiating and anti-apoptotic actions in osteoblasts and its ability to inhibit osteoclastogenesis. LRP1, the receptor that mediates the anabolic actions of lactoferrin in skeletal tissue, functions as a mitogenic signaling receptor in osteoblasts. Lactoferrin may have a physiological role in bone growth, and could be considered as a potential therapeutic agent for bone disorders, such as osteoporosis, and might have utility as a local agent to promote bone repair.

\section{References}

1. Garnero P, Delmas PD. Evaluation of risk for osteoporosis fractures. In: Bilezikian JP, Raisz LG, Rodan GA, eds. Principles of bone biology. 2nd ed. San Diego, CA: Academic Press;2002. 1291-1301.

2. Cummings SR, Melton LJ. Epidemiology and outcomes of osteoporotic fractures. Lancet 2002;359:1761-1767. 
3. Grey A, Reid IR. Emerging and potential therapies for osteoporosis. Exp Opinion Invest Drugs 2005; (in press).

4. Cranney A, Guyatt G, Griffith L, Wells G, Tugwell P, Rosen C; Osteoporosis Methodology Group and The Osteoporosis Research Advisory Group. Meta-analyses of therapies for postmenopausal osteoporosis. IX: Summary of meta-analyses of therapies for postmenopausal osteoporosis. Endocr Rev 2002;23:570-578.

5. Rosen CJ, Bilezikian JP. Clinical review 123: anabolic therapy for osteoporosis. J Clin Endocrinol Metab 2001;86:957-964.

6. Rosen CJ. What's new with PTH in osteoporosis: where are we and where are we headed? Trends Endocrinol Metab 2004; 15:229-233.

7. Metz-Boutigue MH, Jolles J, Mazurier J, Schoentgen F, Legrand D, Spik G, Montreuil J, Jolles P. Human lactotransferrin: amino acid sequence and structural comparisons with other transferrins. Eur J Biochem 1984;145:659-676.

8. Lonnerdal B, Iyer S. Lactoferrin: molecular structure and biological function. Annu Rev Nutr 1995;15:93-110.

9. Dinauer MC, Lekstrom-Himes JA, Dale DC. Inherited neutrophil disorders: molecular basis and new therapies. Hematology (Am Soc Hematol Educ Program) 2000;303-318.

10. Caccavo D, Sebastiani GD, Di Monaco C, Guido F, Galeazzi M, Ferri GM, Bonomo L, Afeltra A. Increased levels of lactoferrin in synovial fluid but not in serum from patients with rheumatoid arthritis. Int J Clin Lab Res 1999;29:30-35.

11. Weinberg ED. Human lactoferrin: a novel therapeutic with broad spectrum potential. J Pharm Pharmacol 2001;53:1303-1310.

12. Bi BY, Lefebvre AM, Dus D, Spik G, Mazurier J. Effect of lactoferrin on proliferation and differentiation of the Jurkat human lymphoblastic T cell line. Arch Immunol Ther Exp (Warsz) 1997;45:315-320.

13. Ward PP, Mendoza-Meneses M, Mulac-Jericevic B, Cunningham GA, Saucedo-Cardenas O, Teng CT, Conneely OM. Restricted spatiotemporal expression of lactoferrin during murine embryonic development. Endocrinology 1999; 140:1852-1860.

14. Sawatzki G, Rich IN. Lactoferrin stimulates colony stimulating factor production in vitro and in vivo. Blood Cells 1989; 15:371-385.

15. Baveye S, Elass E, Fernig DG, Blanquart C, Mazurier J, Legrand D. Human lactoferrin interacts with soluble CD14 and inhibits expression of endothelial adhesion molecules, E-selectin and ICAM-1, induced by the CD14lipopolysaccharide complex. Infect Immun 2000;68:6519-6525.

16. Guillen C, McInnes IB, Vaughan DM, Kommajosyula S, Van Berkel PH, Leung BP, Aguila A, Brock JH. Enhanced Th1 response to Staphylococcus aureus infection in human lactoferrin-transgenic mice. J Immunol 2002;168:3950-3957.

17. Kimber I, Cumberbatch M, Dearman RJ, Headon DR, Bhushan M, Griffiths CE. Lactoferrin: influences on Langerhans cells, epidermal cytokines, and cutaneous inflammation. Biochem Cell Biol 2002;80:103-107.

18. Elass E, Masson M, Mazurier J, Legrand D. Lactoferrin inhibits the lipopolysaccharide-induced expression and proteoglycan-binding ability of interleukin-8 in human endothelial cells. Infect Immun 2002;70:1860-1866.

19. Frydecka I, Zimecki M, Bocko D, Kosmaczewska A, Teodorowska R, Ciszak L, Kruzel M, Wlodarska-Polinsk J, Kuliczkowski K, Kornafel J. Lactoferrin-induced up-regulation of zeta (zeta) chain expression in peripheral blood T lymphocytes from cervical cancer patients. Anticancer Res 2002;22:1897-1901.

20. Baveye S, Elass E, Mazurier J, Spik G, Legrand D. Lactoferrin: a multifunctional glycoprotein involved in the modulation of the inflammatory process. Clin Chem Lab Med 1999;37:281-286.
21. Cornish J, Callon KE, Naot D, Palmano KP, Banovic T, Bava U, Watson M, Lin JM, Tong PC, Chen Q, Chan VA, Reid HE, Fazzalari N, Baker HM, Baker EN, Haggarty NW, Grey $\mathrm{AB}$, Reid IR. Lactoferrin is a potent regulator of bone cell activity and increases bone formation in vivo. Endocrinology 2004; 145:4366-4374.

22. Grey A, Banovic T, Zhu Q, Watson M, Callon K, Palmano K, Ross J, Naot D, Reid IR, Cornish J. The low-density lipoprotein receptor-related protein 1 is a mitogenic receptor for lactoferrin in osteoblastic cells. Mol Endocrinol 2004; 18:2268-2278.

23. Alam AS, Moonga BS, Bevis PJ, Huang CL, Zaidi M. Amylin inhibits bone resorption by a direct effect on the motility of rat osteoclasts. Exp Physiol 1993;78:183-196.

24. Cornish J, Callon KE, Cooper GJ, Reid IR. Amylin stimulates osteoblast proliferation and increases mineralized bone volume in adult mice. Biochem Biophys Res Commun 1995;207:133-139.

25. Cornish J, Gillespie MT, Callon KE, Horwood NJ, Moseley JM, Reid IR. Interleukin-18 is a novel mitogen of osteogenic and chondrogenic cells. Endocrinology 2003;144:1194-1201.

26. Lorget F, Clough J, Oliveira M, Daury MC, Sabokbar A, Offord E. Lactoferrin reduces in vitro osteoclast differentiation and resorbing activity. Biochem Biophys Res Commun 2002;296:261-266.

27. Suzuki YA, Lonnerdal B. Characterization of mammalian receptors for lactoferrin. Biochem Cell Biol 2002;80:75-80.

28. Willnow TE, Goldstein JL, Orth K, Brown MS, Herz J. Low density lipoprotein receptor-related protein and gp330 bind similar ligands, including plasminogen activator-inhibitor complexes and lactoferrin, an inhibitor of chylomicron remnant clearance. J Biol Chem 1992;267:26172-26180.

29. Meilinger M, Haumer M, Szakmary KA, Steinbock F, Scheiber B, Goldenberg H, Huettinger M. Removal of lactoferrin from plasma is mediated by binding to low density lipoprotein receptor-related protein/alpha 2-macroglobulin receptor and transport to endosomes. FEBS Lett 1995;360:70-74.

30. Ji ZS, Mahley RW. Lactoferrin binding to heparan sulfate proteoglycans and the LDL receptor-related protein. Further evidence supporting the importance of direct binding of remnant lipoproteins to HSPG. Arterioscler Thromb 1994;14:2025-2031.

31. Vash B, Phung N, Zein S, DeCamp D. Three complement-type repeats of the low-density lipoprotein receptor-related protein define a common binding site for RAP, PAI-1, and lactoferrin. Blood 1998;92:3277-3285.

32. Strickland DK, Gonias SL, Argraves WS. Diverse roles for the LDL receptor family. Trends Endocrinol Metab 2002;13:66-74.

33. Ziere GJ, van Dijk MC, Bijsterbosch MK, van Berkel TJ. Lactoferrin uptake by the rat liver. Characterization of the recognition site and effect of selective modification of arginine residues. J Biol Chem 1992;267:11229-11235.

34. Goretzki L, Mueller BM. Low-density-lipoprotein-receptorrelated protein (LRP) interacts with a GTP-binding protein. Biochem J 1998;336:381-386.

35. Herz J, Gotthardt M, Willnow TE. Cellular signalling by lipoprotein receptors. Curr Opin Lipidol 2000;11:161-166.

36. Li Y, Cam J, Bu G. Low-density lipoprotein receptor family: endocytosis and signal transduction. Mol Neurobiol 2001;23:53-67.

37. Willnow TE, Armstrong SA, Hammer RE, Herz J. Functional expression of low density lipoprotein receptor-related protein is controlled by receptor-associated protein in vivo. Proc Natl Acad Sci U S A 1995;92:4537-4541. 
38. Willnow TE, Rohlmann A, Horton J, Otani H, Braun JR, Hammer RE, Herz J. RAP, a specialized chaperone, prevents ligand-induced ER retention and degradation of LDL receptor-related endocytic receptors. EMBO J 1996; 15:2632-2639.

39. Gliemann J. Receptors of the low density lipoprotein (LDL) receptor family in man. Multiple functions of the large family members via interaction with complex ligands. Biol Chem 1998;379:951-964.

40. Orr AW, Pedraza CE, Pallero MA, Elzie CA, Goicoechea S, Strickland DK, Murphy-Ullrich JE. Low density lipoprotein receptor-related protein is a calreticulin coreceptor that signals focal adhesion disassembly. J Cell Biol 2003;161:1179-1189.

41. Cornish J. Lactoferrin promotes bone growth. Biometals 2004; 17:331-335.

42. Cornish J, Callon KE, Lin CQ, Xiao CL, Gamble GD, Cooper GJ, Reid IR. Comparison of the effects of calcitonin gene-related peptide and amylin on osteoblasts. J Bone Miner Res 1999;14:1302-1309.

43. Cornish J, Callon KE, Reid IR. Insulin increases histomorphometric indices of bone formation in vivo. Calcif Tissue Int 1996;59:492-495.

44. Cornish J, Callon KE, Coy DH, Jiang NY, Xiao L, Cooper GJ, Reid IR. Adrenomedullin is a potent stimulator of osteoblastic activity in vitro and in vivo. Am J Physiol 1997;273:E1113-1120.

45. Cornish J, Callon KE, Nicholson GC, Reid IR. Parathyroid hormone-related protein-(107-139) inhibits bone resorption in vivo. Endocrinology 1997;138:1299-1304.

46. Hutchens TW, Henry JF, Yip TT. Structurally intact (78-kDa) forms of maternal lactoferrin purified from urine of preterm infants fed human milk: identification of a trypsin-like proteolytic cleavage event in vivo that does not result in fragment dissociation. Proc Natl Acad Sci U S A 1991;88:2994-2998.

47. Zimecki M, Dawiskiba J, Zawirska B, Krawczyk Z, Kruzel M. Bovine lactoferrin decreases histopathological changes in the liver and regulates cytokine production by splenocytes of obstructive jaundiced rats. Inflamm Res 2003;52:305-310.

48. Wakabayashi H, Takakura N, Teraguchi S, Tamura Y. Lactoferrin feeding augments peritoneal macrophage activities in mice intraperitoneally injected with inactivated Candida albicans. Microbiol Immunol 2003;47:37-43.

49. Kumari J, Swain T, Sahoo PK. Dietary bovine lactoferrin induces changes in immunity level and disease resistance in Asian catfish Clarias batrachus. Vet Immunol Immunopathol 2003;94:1-9.

50. Boxio R, Bossenmeyer-Pourie C, Steinckwich N, Dournon C, Nusse O. Mouse bone marrow contains large numbers of functionally competent neutrophils. J Leukoc Biol 2004;75:604-611.

51. Masson PL, Heremans JF. Lactoferrin in milk from different species. Comp Biochem Physiol B 1971;39:119-129.

52. Ward PP, Mendoza-Meneses M, Cunningham GA, Conneely $\mathrm{OM}$. Iron status in mice carrying a targeted disruption of lactoferrin. Mol Cell Biol 2003;23:178-185.

53. Niemeier A, Kassem M, Toedter K, Wendt D, Ruether W, Beisiegel U, Heeren J. Expression of LRP1 by human osteoblasts: a mechanism for the delivery of lipoproteins and vitamin K1 to bone. J Bone Miner Res 2005;20:283-293.

54. Kato M, Patel MS, Levasseur R, Lobov I, Chang BH, Glass DA 2nd, Hartmann C, Li L, Hwang TH, Brayton CF, Lang RA, Karsenty G, Chan L. Cbfa1-independent decrease in osteoblast proliferation, osteopenia, and persistent embryonic eye vascularization in mice deficient in Lrp5, a Wnt coreceptor. J Cell Biol 2002;157:303-314.
55. Gong Y, Slee RB, Fukai N, Rawadi G, Roman-Roman S, Reginato AM, Wang H, Cundy T, Glorieux FH, Lev D, Zacharin M, Oexle K, Marcelino J, Suwairi W, Heeger S, Sabatakos G, Apte S, Adkins WN, Allgrove J, ArslanKirchner M, Batch JA, Beighton P, Black GC, Boles RG, Boon LM, Borrone C, Brunner HG, Carle GF, Dallapiccola B, De Paepe A, Floege B, Halfhide ML, Hall B, Hennekam RC, Hirose T, Jans A, Juppner H, Kim CA, Keppler-Noreuil K, Kohlschuetter A, LaCombe D, Lambert M, Lemyre E, Letteboer T, Peltonen L, Ramesar RS, Romanengo M, Somer H, Steichen-Gersdorf E, Steinmann B, Sullivan B, Superti-Furga A, Swoboda W, van den Boogaard MJ, Van Hul W, Vikkula M, Votruba M, Zabel B, Garcia T, Baron R, Olsen BR, Warman ML; Osteoporosis-Pseudoglioma Syndrome Collaborative Group. LDL receptor-related protein 5 (LRP5) affects bone accrual and eye development. Cell 2001;107:513-523.

\section{Author Affiliations}

Dorit Naot, PhD; Andrew Grey, MD; Ian R. Reid, MD; Jillian Cornish, PhD; Department of Medicine, University of Auckland, Private Bag 92019, Auckland, New Zealand. 